\title{
UMA DÉCADA DE APRENDIZAGEM (1997-2007): \\ O CASO DE SANTIAGO MAIOR (ALANDROAL) ${ }^{1}$
}

\section{Bravo Nico (1), Lurdes Pratas Nico (1,2), Antónia Tobias (1), Florbela Valadas (1,3) \&}

\section{Elisabete Galhardas $(1,3)$}

\section{(1) Universidade de Évora (Centro de Investigação em Educação e Psicologia) / Portugal \\ (2) Direç̧ão Regional de Educação do Alentejo / Portugal \\ (3) Câmara Municipal do Alandroal / Portugal}

\section{jbn@uevora.pt}

Resumo: Qual o universo de aprendizagens que esteve disponível e se concretizou, num determinado território e durante um certo período? Qual o contributo das instituições escolares e não-escolares para a qualificação de uma determinada comunidade? Que estilo de aprendizagem eventualmente construíram os indivíduos residentes num determinado território e pertencentes a uma comunidade concreta? Foram estas algumas das questões de partida que balizaram o projecto de investigação "Arqueologia das Aprendizagens no Alandroal" - promovido pelo Centro de Investigação em Educação e Psicologia da Universidade de Évora e financiado pela Fundação para a Ciência e a Tecnologia - que está em curso no concelho do Alandroal (um município do sul de Portugal, com $545 \mathrm{Km}^{2}$ de área geográfica, uma população aproximada de 6000 indivíduos e constituído por 6 freguesias) e cujos resultados têm vindo a ser, regularmente, divulgados.

A presente comunicação responde às questões anteriores, no que se refere à comunidade de Santiago Maior (uma das freguesias do concelho do Alandroal/Portugal). Aqui se apresentam, de forma parcial, o universo de aprendizagens institucionais que, no período 19972007, as instituições escolares e não-escolares disponibilizaram à população, bem como alguns aspectos do respectivo perfil.

\section{O sítio das aprendizagens}

A aprendizagem é uma realidade humana presente na circunstância vital de cada indivíduo, que este concretiza no respectivo quotidiano. Assim sendo, a aprendizagem está presente na vida do dia-a-dia das pessoas, independentemente dos diferentes contextos em que estas se movimentam: na família, na escola, na profissão, no associativismo, na política, no desporto, no lazer, na amizade, etc.

\footnotetext{
${ }^{1}$ Comunicação integrada no âmbito do Projecto de investigação denominado "Arqueologia das Aprendizagens no Alandroal", promovido pelo Centro de Investigação em Educação e Psicologia da Universidade de Évora e financiado pela Fundação para a Ciência e a Tecnologia (refa PTDC/CED/81388/2006).
} 
Os espaços e tempos especificamente pensados e estruturados para que neles aconteça a aprendizagem são apenas uma pequena parte da circunstância de cada indivíduo. Na realidade, a vida está preenchida de ocasiões (diversas, inorgânicas mas ricas) onde podem ocorrer aprendizagens. As trajectórias vitais de cada indivíduo comportam sempre um significativo conjunto de aprendizagens que não foram realizadas nos chamados contextos formais de educação e formação (Nico \& Nico, 2011: 211).

O conhecimento, num determinado território, da rede de oportunidades de aprendizagem contemplando todas possíveis modalidades de educação e formação e respectivos agentes promotores - tem vindo a revelar-se uma análise importante, pois ela permite avaliar do potencial educativo desse território. Por outro lado, o conhecimento pormenorizado desse mapa poderá permitir um exercício de meta-análise e meta-avaliação da própria realidade, no sentido de esta ser pensada de uma forma mais integrada e racional. Este exercício é, em nossa opinião, decisivo para que cada território assuma um protagonismo diferente na sua própria qualificação, enquanto contexto promotor da qualificação das instituições e das pessoas que nele existem.

Conhecer o mapa das aprendizagens existente em cada território, incluindo no perímetro desse exercício de cartografia educacional, todas as manifestações educativas e formativas aí existentes é, na actualidade e em nossa opinião, o primeiro passo de um diálogo sério, simbiótico e coordenador entre as políticas de qualificação e respectivos instrumentos e os territórios, as instituições e as pessoas neles residentes (Nico, 2008: 16; Bier, Chambon \& Queiroz, 2010: 129; Nico, 2011: 145).

\section{O projecto "Arqueologia das Aprendizagens no Alandroal"}

Guiada pelo princípio enunciado no anterior parágrafo, em 2007, uma equipa de investigação do Centro de Investigação em Educação e Psicologia da Universidade de Évora rumou ao Alandroal (município do Sul de Portugal) e aí estabeleceu uma base de trabalho (em parceria formal com a Direcção Regional de Educação do Alentejo e a Câmara Municipal do Alandroal). A questão de partida era simples: qual o universo de aprendizagens disponível e concretizado pela população adulta do Alandroal, no período 1997-2007?

A pesquisa foi organizada em duas fileiras que se sucederam:

i) A sinalização de todas as instituições existentes no território e consequente identificação e caracterização de todas as actividades de aprendizagem que aquelas tivessem disponibilizado, no período considerado;

ii) O recenseamento da população adulta do concelho, o estabelecimento de uma amostra representativa e a identificação e caracterização do universo de aprendizagens concretizado por essa população, no período considerado.

Entre 2007 e 2010, foi realizado o trabalho no terreno, tendo resultado um exaustivo conjunto de informações que caracterizam os universos de aprendizagens existente e 
concretizado no concelho e cada uma das seis freguesias que o constituem (Nossa Senhora da Conceição, Santiago Maior, Terena, Capelins, São Brás dos Matos e Juromenha), no período 1997-2007.

\section{As instituições na freguesia de Santiago Maior}

A presente comunicação apresenta os resultados (parcelares) relativos à freguesia de Santiago Maior, nomeadamente os que respeitam à dimensão das aprendizagens institucionais

Foram inquiridas 89 instituições na freguesia em estudo, distribuídas pelas áreas de actividade que se apresentam na Tabela 1.

Tabela1 - Área de actividade das instituições

\begin{tabular}{||l||c|c||}
\hline \multicolumn{1}{|c||}{ Área de Actividade das instituições } & N & $\%$ \\
\hline \hline Agricultura, produção animal, caça, floresta e pesca & 9 & 10,1 \\
\hline Indústrias transformadoras & 20 & 22,5 \\
\hline \hline Construção & 10 & 11,2 \\
\hline \hline \begin{tabular}{l|c} 
Comércio por grosso e a retalho; reparação de veículos automóveis e \\
motociclos
\end{tabular} & 15 & 16,9 \\
\hline \hline Alojamento, restauração e similares & 23 & 25,8 \\
\hline Actividades Financeiras e de Seguros & 1 & 1,1 \\
\hline \hline Actividades Administrativas e dos serviços de apoio & 1 & 1,1 \\
\hline \hline Administração Pública e defesa; segurança social obrigatória & 2 & 2,2 \\
\hline \hline Actividades de saúde humana e apoio social & 1 & 1,1 \\
\hline Actividades Artísticas, de espectáculos, desportivas e recreativas & 6 & 6,7 \\
\hline \hline Outras actividades e serviços & 1 & 1,1 \\
\hline \hline Total & $\mathbf{8 9}$ & $\mathbf{1 0 0 , 0}$ \\
\hline \hline
\end{tabular}

Como se pode depreender da análise da informação apresentada anteriormente, a área das actividades relativas à restauração e comércio diverso predomina, com um total de 38 instituições (42,7\% do total). Também com uma presença significativa no universo considerado, encontramos as pequenas indústrias transformadoras, com 20 instituições (22,5\% do total). De referir que a freguesia de Santiago Maior é uma das freguesias com maior presença de empresas no concelho do Alandroal, o que lhe confere uma dinâmica empreendedora assinalável.

Esta constatação é comprovada pela análise da natureza jurídica das instituições inquiridas (cf. Tabela 2), onde podemos constatar que, na freguesia em estudo, as empresas predominam, com 71 unidades inquiridas (correspondendo a cerca de $80 \%$ ). 
Tabela 2 - Natureza jurídica das instituições

\begin{tabular}{|c|c|c|}
\hline Natureza Jurídica & $\mathbf{N}$ & $\%$ \\
\hline Autarquia & 1 & 1,1 \\
\hline Instituição Particular de Solidariedade Social & 2 & 2,2 \\
\hline Associação de Desenvolvimento Local & 1 & 1,1 \\
\hline Associação Cultural e/ou Desportiva & 6 & 6,7 \\
\hline Associação Juvenil & 1 & 1,1 \\
\hline Empresa & 71 & 79,8 \\
\hline Cooperativa & 2 & 2,2 \\
\hline Outra & 3 & 3,4 \\
\hline Sem resposta & 2 & 2,2 \\
\hline Total & 89 & 100,0 \\
\hline
\end{tabular}

De referir que as pequenas unidades industriais, de dimensão quase sempre familiar são as empresas mais comuns no território estudado. As pequenas unidades de produção de queijo, enchidos tradicionais e de panificação assumem-se como a fileira mais importante no local. Em seguida, são de relevar as pequenas e microempresas de natureza comercial e de restauração.

Relativamente à antiguidade das instituições, como se pode depreender da análise da informação constante na Figura 1, verifica-se uma certa juventude na vida institucional, sendo de realçar os anos de 2000, 2001 e 1998, como sendo os anos em que foram constituídas mais instituições $(8,6$ e 5 , respectivamente).

Figura 1 - Ano de fundação das instituições

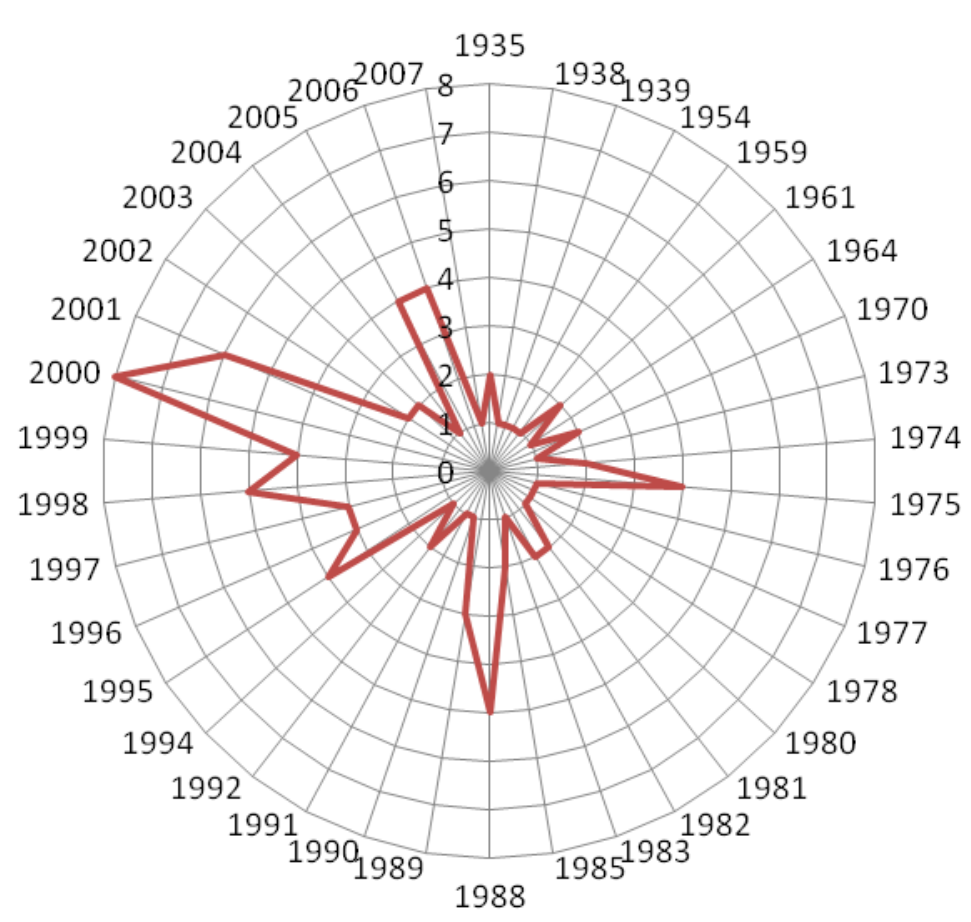


No âmbito da sua actividade, a maioria das instituições da freguesia de Santiago Maior (aproximadamente 55\% do total) não estabeleceu qualquer parceria com outras instituições, como se pode verificar através da informação constante na Figura 2. No caso em que este relacionamento se verificou ( $45 \%$ do total), cerca de $30 \%$ das parcerias foram estabelecidas formalmente, através da celebração de protocolos.

Figura 2 - Parcerias

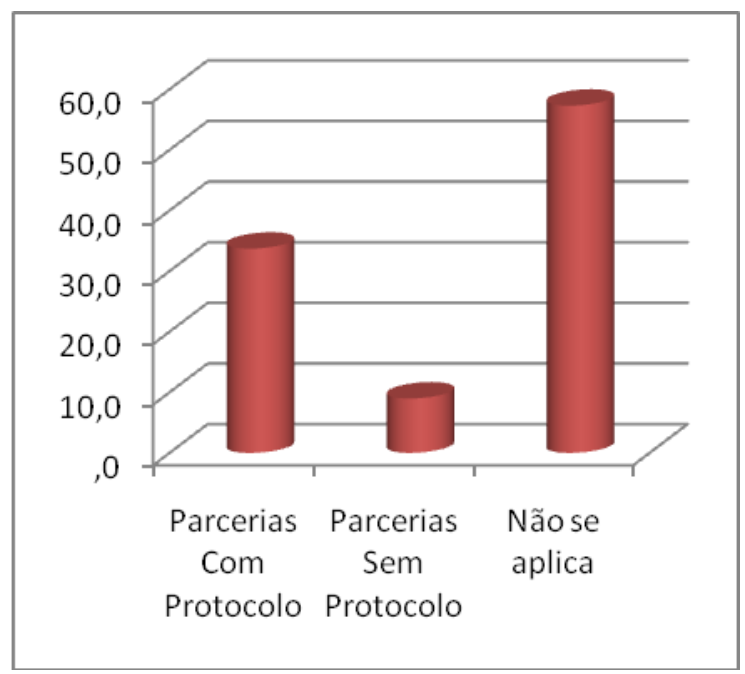

\section{As aprendizagens institucionais na freguesia de Santiago Maior}

Nas 89 instituições inquiridas foi possível identificar e caracterizar um conjunto de 268 aprendizagens disponibilizadas no período de 1997 a 2007. O critério utilizado assentou num conceito de aprendizagem assumido como sendo um espaço e um tempo estruturados com uma intencionalidade educativa ou formativa minimamente estruturada e sequenciada, independentemente da sua natureza, do seu promotor e da natureza e grau de certificação.

Quando analisamos as áreas em que as instituições disponibilizaram aprendizagens à população do território em estudo, verificamos que, de acordo com a informação disponibilizada pela Figura 3, existem quatro importantes grupos de aprendizagens identificados no conjunto de aprendizagens identificadas:

i) O grupo maquinaria/veículos/aparelhos: nesta dimensão, encontramos todas as aprendizagens decorrentes da necessidade de saber operar os novos equipamentos e aparelhos adquiridos no âmbito das unidades empresariais já identificadas;

ii) $\mathrm{O}$ grupo qualidade/segurança/higiene no trabalho: nesta dimensão, encontram-se as aprendizagens envolvidas nos processos de formação dos proprietários e trabalhadores que determinam a atribuição de 
licenças de funcionamento às empresas de produção ou comercialização de produtos alimentares. Neste grupo de aprendizagens, ganha natural preponderância o processo conhecido como HACCP (Hazard Analysis and Critical Control Point ou, em português, o processo de Análise de Perigos e Pontos Críticos de Controle/APPCC);

iii) $\mathrm{O}$ grupo das aprendizagens comercial, que decorre da significativa existência de estabelecimentos comerciais e da necessidade de os seus proprietários e trabalhadores promoverem, de forma regular, alguma formação no âmbito dos produtos que comercializam e do próprio funcionamento interno desses estabelecimentos (contabilidade, procedimentos administrativos, etc.);

iv) O grupo de aprendizagens alimentar, que é o resultado da actividade dos estabelecimentos de restauração.

Figura 3 - "Cluster" das aprendizagens institucionais

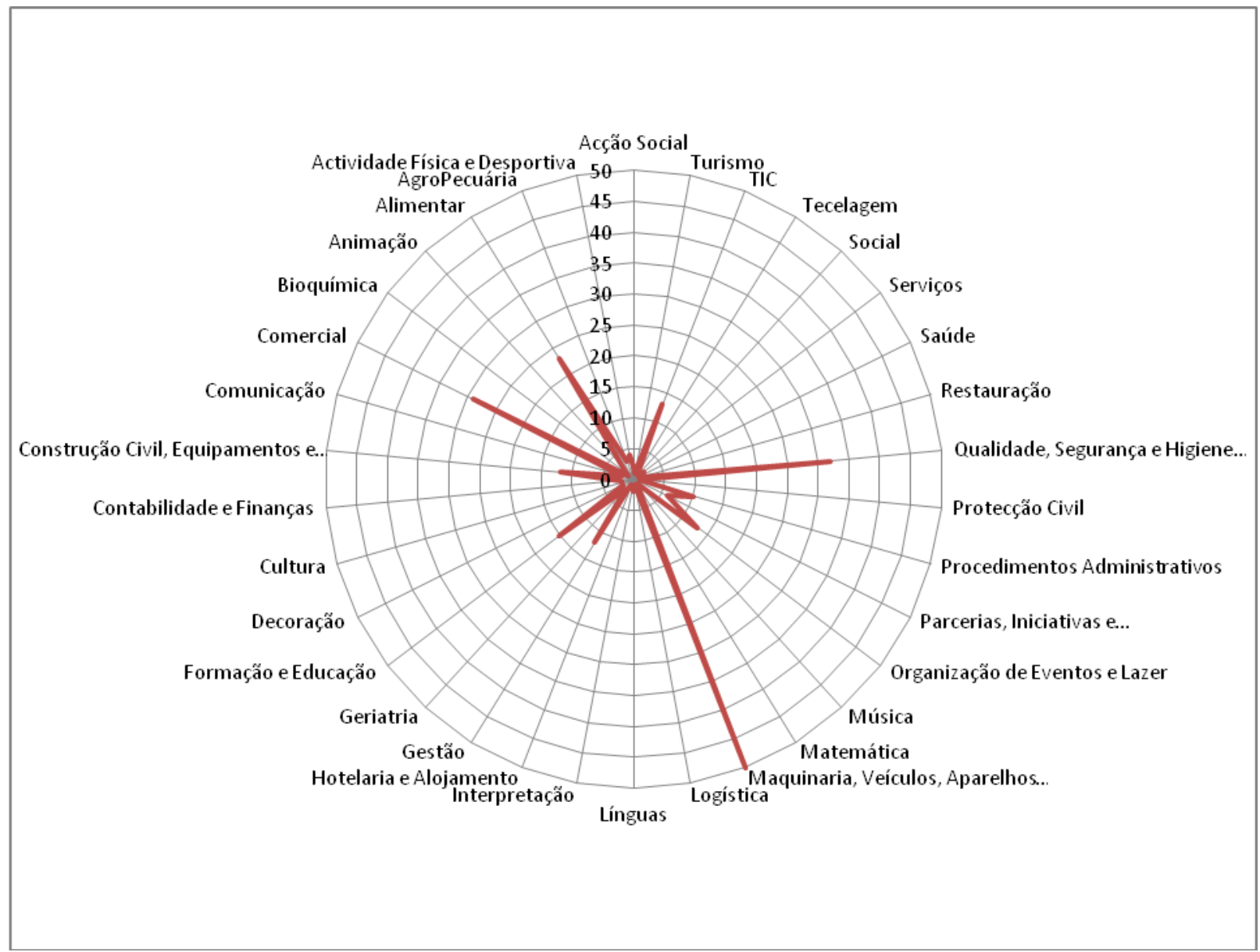

Quando se determina a distribuição cronológica do momento em que as aprendizagens institucionais foram disponibilizadas (cf. Figura 4), verificamos que a evolução foi sempre de 
sinal positivo e teve, no ano 2007, o ano de maior número de aprendizagens disponibilizadas (90 ocorrências, o que representa $34,2 \%$ do total).

Figura 4-Momento de disponibilização das aprendizagens institucionais

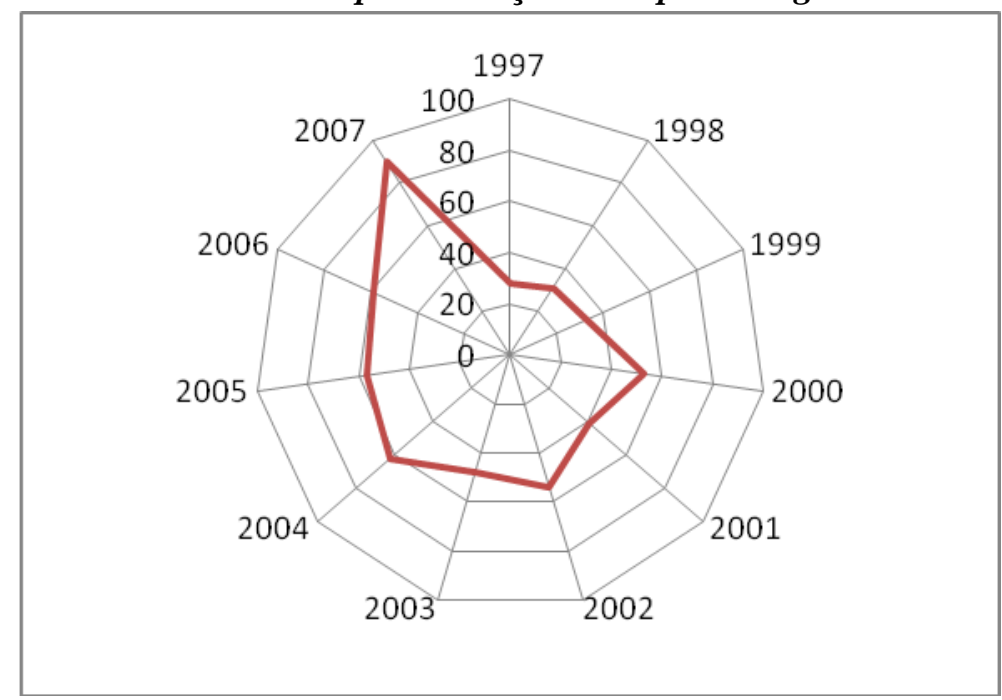

Aspecto bastante importante no exercício de cartografia das aprendizagens institucionais que aqui se apresenta é o que se relaciona com os objectivos indicados para as aprendizagens institucionais identificadas e caracterizadas. Neste âmbito, ao observar-se a Figura 5, podemos verificar que, uma vez mais, a dimensão empresarial/profissional se assume como a mais relevante. De facto, objectivos relacionados com a modernização da instituição, a formação profissional e a formação do pessoal assumem um peso de 30,6\%, 22,8\% e 17,9\%, respectivamente, do total considerado.

Figura 5 - Objectivos das aprendizagens institucionais

Formação Escolar


O tipo de certificação das aprendizagens institucionais reparte-se entre a certificação formal profissional e a certificação informal de natureza laboral (a que se concretiza com o exercício profissional do indivíduo).

\section{Figura 6 - Tipo de certificação das aprendizagens institucionais}

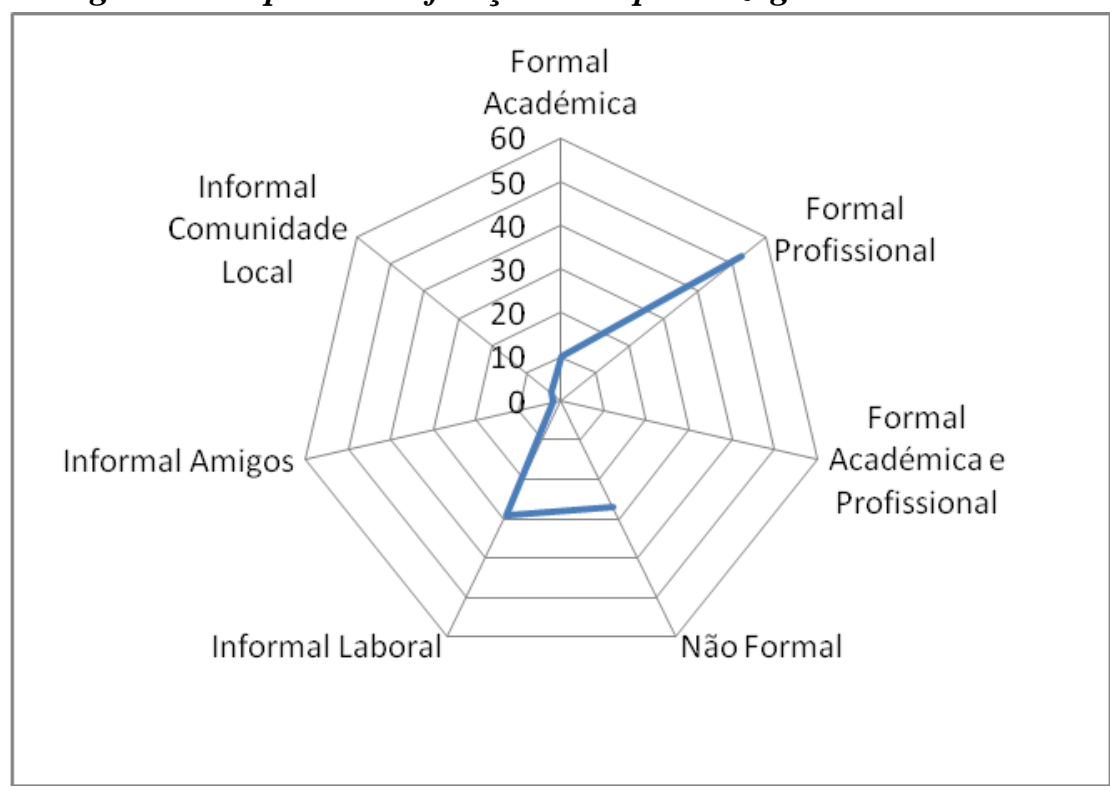

No que se refere à natureza da participação dos indivíduos nas aprendizagens institucionais, verificamos, pela análise da Figura 7 que a maioria das aprendizagens não pressupõe a obrigatoriedade da participação (158 aprendizagens, a que corresponde $59 \%$ dos casos identificados).

Figura 7 - Natureza da participação

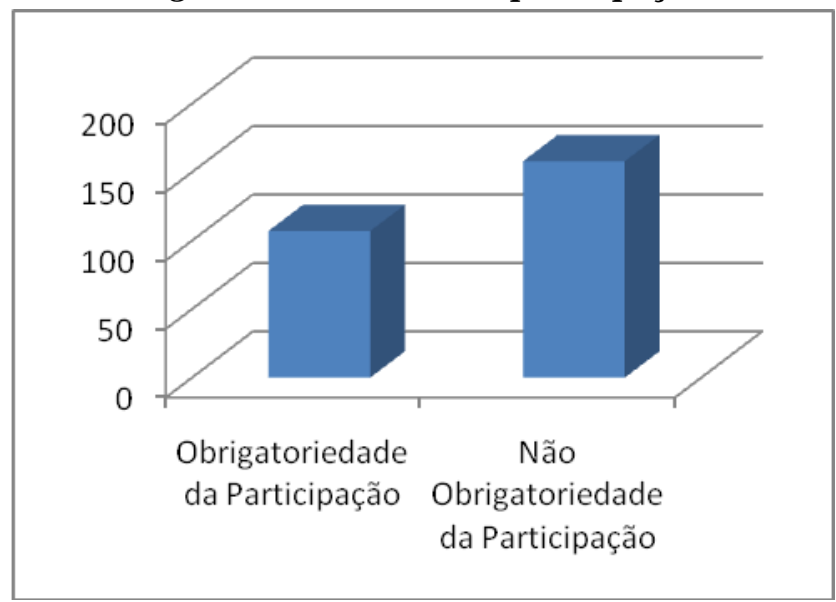

\section{Conclusão}

Deste pequeno (e incompleto) exercício de cartografia educacional no território correspondente à freguesia de Santiago Maior (Alandroal), no período 1997-2007, podemos 
retirar algumas conclusões, que se nos afiguram ser interessantes, tendo em vista a nossa questão inicial:

i. a existência de um universo significativo de aprendizagens institucionais (268 episódios de aprendizagem identificados);

ii. o peso significativo das aprendizagens relacionadas com a actividade empresarial e o consequente desempenho profissional dos proprietários e trabalhadores das empresas locais;

iii. o papel que os novos equipamentos/aparelhos/tecnologias parecem desempenhar no despoletar de oportunidades de aprendizagem institucional;

iv. a ausência de certificação académica das aprendizagens identificadas e a relevância relativa da certificação profissional, em comparação com os mais comuns processos de certificação não formal e informal;

\section{Referências Bibliográficas}

BIER, B., CHAMBON, A. \& QUEIROZ, JM. (2010). Mutations territoriales et éducation: de la forme scolaire vers la forme éducative?. Issy-les Moulineaux: ESF Éditeur

NICO, B. (2008). "Aprender no interior português: vértices para um pensamento integrado e uma acção responsável". in Bravo Nico (org.) Aprendizagens do interior: reflexões e fragmentos. Mangualde: Edições Pedago

NICO, B. \& NICO, L. (2011). "Qualificação de Adultos no interior sul de Portugal: para onde? in Bravo Nico \& Lurdes Nico (Orgs.). Qualificação de Adultos: realidades e desafios no Sul de Portugal. Mangualde: Edições Pedago

NICO, L. (2011). A Escola da Vida: Reconhecimento dos Adquiridos Experienciais em Portugal. Fragmentos de Uma Década (2000-2010). Mangualde: Edições Pedago. 